\title{
Outorga e suas implicações na piscicultura no entorno do reservatório de Furnas
}

\author{
Grant and its implications on fish farming around the Furnas reservoir
}

\author{
Franciny Oliveira de Deus \\ Mestranda do Programa de Pós-Graduação em Geografia \\ da Universidade Federal de Alfenas - UNIFAL-MG, Brasil \\ ofranciny@yahoo.com.br \\ Marcelo de Oliveira Latuf \\ Professor do Programa de Pós-Graduação em Geografia \\ da Universidade Federal de Alfenas - UNIFAL-MG, Brasil \\ marcelo.latuf@unifal-mg.edu.br
}

\section{Resumo}

A gestão de recursos hídricos é urgente e permite atender às demandas econômicas, sociais e ambientais. Entretanto, muitas vezes, surgem conflitos em relação ao seu uso. A água é um bem de uso comum do povo, portanto, ela é de domínio público, mas para que ocorra um consumo em níveis sustentáveis é necessário obter autorização, quando se trata de intervenção em um corpo hídrico, relativa à quantidade, qualidade ou regime das águas, essa autorização é denominada de Outorga de Direito de Uso de Recursos Hídricos. Na piscicultura a outorga tem papel fundamental, pois ela regularizará a prática do cultivo de peixes e contribuirá para evitar que corpos hídricos sejam contaminados com o descarte irregular dos resíduos do cultivo.

Palavras-chave: Política Nacional de Recursos Hídricos, Usos múltiplos, Economia da água.

\begin{abstract}
The management of water resources is urgent and allows to meet the economic, social and environmental demands. However, conflicts often arise concerning its use. Water is a common good; therefore it is in the public domain, but for consumption to occur at sustainable levels it is necessary to obtain authorization when it comes to intervention in a water body, concerning quantity, quality or regime of water, this authorisation is called Granting of Right to Use Water Resources. In fish farming the grant has a fundamental role since it will regularise the practice of fish farming and will help prevent water bodies from being contaminated with the irregular disposal of crop residues.
\end{abstract}

Keywords: National Water Resources Policy, Multiple uses, Water economy.

\section{INTRODUÇÃO}

A água é um recurso natural que pertence ao domínio público. De acordo com a Constituição da República Federativa do Brasil, de 1988, (Arts. 20, III e 26, I) as águas de lagos, rios e as águas subterrâneas constituem bens ou da União ou dos Estados. Para evitar conflitos em relação aos diversos usos da água e obter uma gestão sustentável dos recursos hídricos, o Poder Público tem responsabilidade de administrar qualquer intervenção que seja realizada em um corpo 
de água, para isso, é necessário ter a autorização denominada Outorga de Direito de Uso de Recursos Hídricos.

A Outorga de Direito de Uso de Recursos Hídricos é um dos instrumentos da Política Nacional de Recursos Hídricos, estabelecido no inciso III, artigo $5^{\circ}$ da Lei Federal 9.433, de 08 de janeiro de 1997, bem como da Política Estadual de Recursos Hídricos de Minas Gerais, nos termos do inciso V, artigo $9^{\circ}$ da Lei Estadual 13.199, de 29 de janeiro de 1999. O instrumento de outorga tem por objetivos assegurar os controles qualitativo e quantitativo dos usos da água e o efetivo exercício dos direitos de acesso à água.

De acordo com o IGAM (Instituto Mineiro de Gestão de Águas), a Outorga é o instrumento legal que assegura ao usuário o direito de utilizar os recursos hídricos, no entanto, essa autorização não dá ao usuário a propriedade da água, mas, sim, o direito de seu uso. Portanto, a outorga poderá ser suspensa, parcial ou totalmente, em casos extremos de escassez, de não cumprimento pelo outorgado dos termos de outorga, por necessidade premente de se atenderem aos usos prioritários e de interesse coletivo, dentre outras hipóteses previstas na legislação vigente.

A Outorga se mostra como fundamental instrumento de gestão dos recursos hídricos, portanto, se faz necessário conhecer suas implicações na gestão dos sistemas produtivos mediante sua natureza de ato administrativo autorizativo com o qual o Poder Público faculta ao outorgado fazer uso da água por determinado tempo.

Diante do exposto, o presente artigo tem por objetivo apresentar fundamentação teórica para utilização do instrumento de outorga no uso de recursos hídricos no entorno do Reservatório de Furnas em relação à piscicultura.

Como metodologia, optou-se pela pesquisa documental, realizada por meio de levantamento bibliográfico (tecnológico, teórico, legislativo e de dados da Administração Pública) acerca dos conceitos e instrumentos relativos à gestão de recursos de Outorga de Direito de Uso dos Recursos Hídricos e suas implicações na piscicultura. Foram analisados: os fundamentos e diretrizes da Política Nacional e da Política Estadual de Recursos Hídricos; os instrumentos de gestão de recursos hídricos; a outorga de direito de uso de recursos hídricos; e a gestão hídrica na piscicultura.

\section{OUTORGA DE DIREITO DE USO DOS RECURSOS HÍDRICOS}

A Política Estadual de Recursos Hídricos prevê a existência de nove instrumentos de gestão, que apresentam natureza predominantemente técnica, conforme consta do artigo $9^{\circ}$, da Lei Estadual 13.199, de 29 de janeiro de 1999: 
Art. $9^{\circ}$ - São instrumentos da Política Estadual de Recursos Hídricos:

I - o Plano Estadual de Recursos Hídricos;

II - os Planos Diretores de Recursos Hídricos de Bacias Hidrográficas;

III - o Sistema Estadual de Informações sobre Recursos Hídricos;

IV - o enquadramento dos corpos de água em classes, segundo seus usos preponderantes;

V - a outorga dos direitos de uso de recursos hídricos;

VI - a cobrança pelo uso de recursos hídricos;

VII - a compensação a municípios pela exploração e restrição de uso de recursos hídricos;

VIII - o rateio de custos das obras de uso múltiplo, de interesse comum ou coletivo;

IX - as penalidades (MINAS GERAIS, 1999).

A outorga atualmente é palco de muitas discussões quanto ao seu deferimento. Quando se pretende intervir significativamente em qualquer corpo hídrico, depende-se de outorga do Poder Público e, quando essa autorização é indeferida, surgem diversos conflitos em relação à sua aplicabilidade.

Para Meirelles (2006) "a outorga trata-se de manifestação unilateral de vontade da Administração Pública que tenha por finalidade adquirir, resguardar, transferir, modificar, extinguir e declarar direitos, ou impor obrigações aos administrados ou a si própria”. Nesse sentido, é o Poder Público que avalia o deferimento ou o indeferimento do pedido da autorização para a intervenção no corpo hídrico.

A competência para praticar o ato administrativo de outorga obedece aos ditames contidos nos artigos 20, inciso III; 26, inciso I e 32, $\S 1^{\circ}$, todos da Constituição Federal. A outorga das águas superficiais é de competência da União e dos Estados. Compete à União a outorga de direito de uso das águas dos lagos, rios e quaisquer correntes de água em terrenos de domínio da União ou que banhem mais de um Estado, sirvam de limite com outros países, ou se estendam a território estrangeiro ou dele provenham. Compete aos Estados proceder à outorga de direito de uso das águas superficiais que estiverem sob seu domínio, ressalvada a competência da União. Por sua vez, a outorga das águas subterrâneas compete apenas aos Estados.

Segundo o Manual Técnico e Administrativo de Outorga de Direito de Uso de Recursos Hídricos no Estado de Minas Gerais (IGAM, 2010), os usos de recursos hídricos que alteram a quantidade de água existente em um corpo hídrico são as captações, as derivações e os desvios. Tais usos somente poderão ser outorgados se houver disponibilidade hídrica, considerados os usos já outorgados a montante e a jusante de determinada seção do curso de água. Avalia-se então o balanço hídrico na seção considerada, tendo-se por base a vazão de Outorga de Direito de Uso dos Recursos Hídricos e suas implicações na Atividade Agropecuária referência adotada pelo Estado e verificadas as finalidades a que se destinam as águas captadas, derivadas ou desviadas, de acordo com procedimentos e critérios definidos para cada finalidade de uso.

É importante destacar que a outorga confere ao usuário apenas o direito de uso de parcela do corpo de água, condicionado à disponibilidade hídrica existente no ponto de intervenção, 
portanto, o usuário outorgado não passa a ser proprietário exclusivo dos recursos hídricos, porque a outorga não corresponde à sua alienação parcial, ela apenas autoriza a captação de água por um determinado período de tempo.

A outorga de direito de uso dos recursos hídricos poderá ser suspensa, parcial ou totalmente, em definitivo ou por prazo determinado, em caso de descumprimento, pelo outorgado, dos termos da outorga. Há também outras hipóteses de suspensão, tais como: a não utilização da água por três anos consecutivos; a necessidade premente de água para atender a situações de calamidade, inclusive as decorrentes de condições climáticas adversas; a necessidade de se prevenir ou fazer reverter grave degradação ambiental; a necessidade de se atender a usos prioritários, de interesse coletivo, para os quais não se disponha de fontes alternativas e as necessidades de se manterem as características de navegabilidade do corpo de água.

De acordo com a Lei Delegada Estadual 180, de 20 de janeiro de 2011 (MINAS GERAIS, 2011), compete às Superintendências Regionais de Regularização Ambiental - SUPRAMs, órgãos que compõem a estrutura básica da Secretaria de Estado de Meio Ambiente e Desenvolvimento Sustentável de Minas Gerais - SEMAD-MG, analisar os processos de Outorga de Direito de Uso dos Recursos Hídricos e suas implicações na Atividade Agropecuária, regularização ambiental do Estado de Minas Gerais, dentre eles, os relativos ao uso dos recursos hídricos.

A SUPRAM, antes de deferir a outorga de direito de uso dos recursos hídricos, procede à análise jurídica dos processos, verificando o preenchimento dos requisitos legais impostos, e à análise técnica, a qual compreende a análise quantitativa e qualitativa da água e a verificação dos estudos hidráulicos e hidrológicos apresentados. Entretanto, em se tratando de outorga dos direitos de uso de recursos hídricos para empreendimentos de grande porte e com potencial poluidor, em Minas Gerais será necessária a aprovação do respectivo comitê de bacia hidrográfica.

No Estado de Minas Gerais, em respeito ao princípio da publicidade, para assegurar o interesse da coletividade e dar efetiva transparência à outorga, os principais atos do procedimento são publicados, quais sejam, o pedido e a concessão ou o indeferimento do pedido de outorga de direito de uso dos recursos hídricos. A outorga tem por finalidade principal garantir disponibilidade hídrica para as demandas existentes e as demandas futuras, possibilitando-se o desenvolvimento econômico sustentável, o abastecimento público e a preservação do meio ambiente para as presentes e futuras gerações.

Quando a outorga é concedida, é necessário ocorrer a efetiva utilização da água, evitandose, assim, que a outorga seja requerida apenas com a finalidade de garantir usos futuros ou impedir que terceiros utilizem-se da água. 


\subsection{Implicações da outorga na piscicultura}

A prática da aquicultura, notadamente a piscicultura, pode ocorrer em tanques escavados, às margens de rios ou reservatórios, ou em tanques-rede, os quais são geralmente instalados dentro de reservatórios.

$\mathrm{Na}$ aquicultura praticada em tanques escavados tem-se, na prática, o desenvolvimento de uma atividade que necessita de outorga para captação de água para adução até os tanques e de outorga para lançamento dos efluentes provenientes dos tanques. As demandas de água levarão em conta as características principais do sistema, como a área de espelho d'água, o volume de armazenamento e a taxa de renovação diária de água. Deverão ser consideradas também as perdas hídricas por infiltração e evaporação.

De acordo com o Manual Técnico e Administrativo de Outorga de Direito de Uso de Recursos Hídricos no Estado de Minas Gerais (IGAM, 2010), na análise técnica deverá ser verificada a disponibilidade hídrica existente na seção do corpo hídrico considerado em relação à vazão de referência e relativamente aos usuários instalados a jusante da intervenção pretendida. Para quantificação da demanda de água para a prática da piscicultura, o requerente deverá especificar o volume dos tanques a serem abastecidos e a lâmina de água a ser mantida para a prática da atividade. A demanda de água poderá ser obtida a partir da seguinte expressão:

$$
\text { Qdem }=A \times N
$$

Sendo:

Qdem = vazão demandada $\left(\mathrm{m}^{3} \cdot \mathrm{s}^{-1} \mathrm{ou} \mathrm{m}^{3} \cdot \mathrm{h}^{-1}\right)$

$\mathrm{A}=$ área de lâmina d'água dos tanques (ha)

$\mathrm{N}=$ necessidade mínima de água por hectare $\left(\mathrm{m}^{3} / \mathrm{h}\right.$. ha $)$

O requerente deverá apresentar informações relativas ao empreendimento para a piscicultura a ser praticada, seus estágios, espécies animais, quantidades, etc., que permitam ao analista a verificação do uso racional da água.

Os pedidos de outorga de direito de uso de recursos hídricos para aquicultura em tanquesrede destinam-se, em sua maioria, à produção de tilápias em barramentos sem captação de água. Tais pedidos deverão ser analisados em função da capacidade do corpo hídrico de diluir a carga de fósforo gerada nos empreendimentos de piscicultura, de modo que não haja alterações negativas na qualidade da água e não se desrespeite a classe de enquadramento do corpo hídrico.

$\mathrm{Na}$ análise dos processos de outorga torna-se necessária, em casos determinados, a vinculação de cuidados e/ou ações condicionantes a serem atendidas pelos usuários após a 
publicação da respectiva Portaria de outorga de direito de uso de recursos hídricos. O cumprimento das condicionantes deve ser comprovado por meio de relatório técnico, com a respectiva Anotação de Responsabilidade Técnica - ART, sob pena de suspensão da outorga de direito de uso de recursos hídricos, conforme expresso no parágrafo segundo do Art. $9^{\circ}$ da Portaria IGAM $n^{\circ}$ 49/2010. Não se aplicam no rol das condicionantes a serem vinculadas a uma Portaria de outorga algumas exigências usualmente praticadas, tais como:

- $\quad$ condicionantes relacionadas com o porte e o potencial poluidor dos empreendimentos, ou seja, propostas de mitigação dos impactos ambientais, que deverão ser descritas nos respectivos processos de autorização ambiental de funcionamento ou de licenciamento ambiental;

- condicionantes relacionadas à compensação ambiental, tais como conversão de recursos financeiros em benefício da preservação de áreas de recarga, de recuperação de vegetação ciliar, de estabilização de voçorocas ou proteção e recuperação de nascentes;

- outras condicionantes que não se aplicam à gestão dos recursos hídricos, eventualmente contidos nos Programas de Controle Ambiental, sobre as quais não se tenha efetivo controle ou ação compatível com o descumprimento da obrigação por parte do usuário outorgado (IGAM, 2010, p. 46).

A discussão em torno da aquicultura vem criando destaque em função do possível descarte incorreto da água dos tanques de criação, pois é preciso trocar essa água periodicamente e se não houver o manejo adequado pode ocorrer a contaminação dos corpos hídricos.

\section{LOCALIZAÇÃO DA ÁREA DE ESTUDO}

A Bacia Hidrográfica do Entorno do Reservatório de Furnas compreende uma área de aproximadamente $16.507 \mathrm{~km}$ é composta por 48 municípios com população estimada, segundo IBGE (2009), de 842.260 habitantes. Apenas $76 \%$ da área total dos municípios compõem a bacia, ou seja, 21 deles encontram-se integralmente inseridos nos limites territoriais da unidade e do restante apenas parcelas de suas áreas municipais estão dentro desses limites.

A bacia do Entorno do Reservatório de Furnas consiste em uma sub-bacia do rio Grande, abrangendo praticamente todo o reservatório da Usina Hidroelétrica de Furnas (UHE FURNAS). Dessa forma, a hidrografia dessa unidade de gestão é composta pelo reservatório, abastecido por rios de maior porte, como o Rio Grande, Rio Sapucaí, Rio do Jacaré e Rio Verde, que não fazem parte desta unidade de gestão, e diversos rios de pequeno e médio porte integralmente localizados nos limites da unidade, configurando a rede de drenagem (Figura 1). Antes da existência do 
reservatório esses rios eram afluentes principalmente dos Rios Sapucaí e Grande, tendo sido alterada completamente a configuração hidrográfica do local.

O reservatório de Furnas é um dos maiores do Brasil com $1.442 \mathrm{~km}^{2}$ e $3.500 \mathrm{~km}$ de perímetro na sua cota máxima, banhando 34 municípios e uma população total de aproximadamente 800.000 habitantes. Esse reservatório é basicamente formado por dois "braços" que correspondem ao Rio Grande e ao Rio Sapucaí, além de vários outros rios contribuintes.

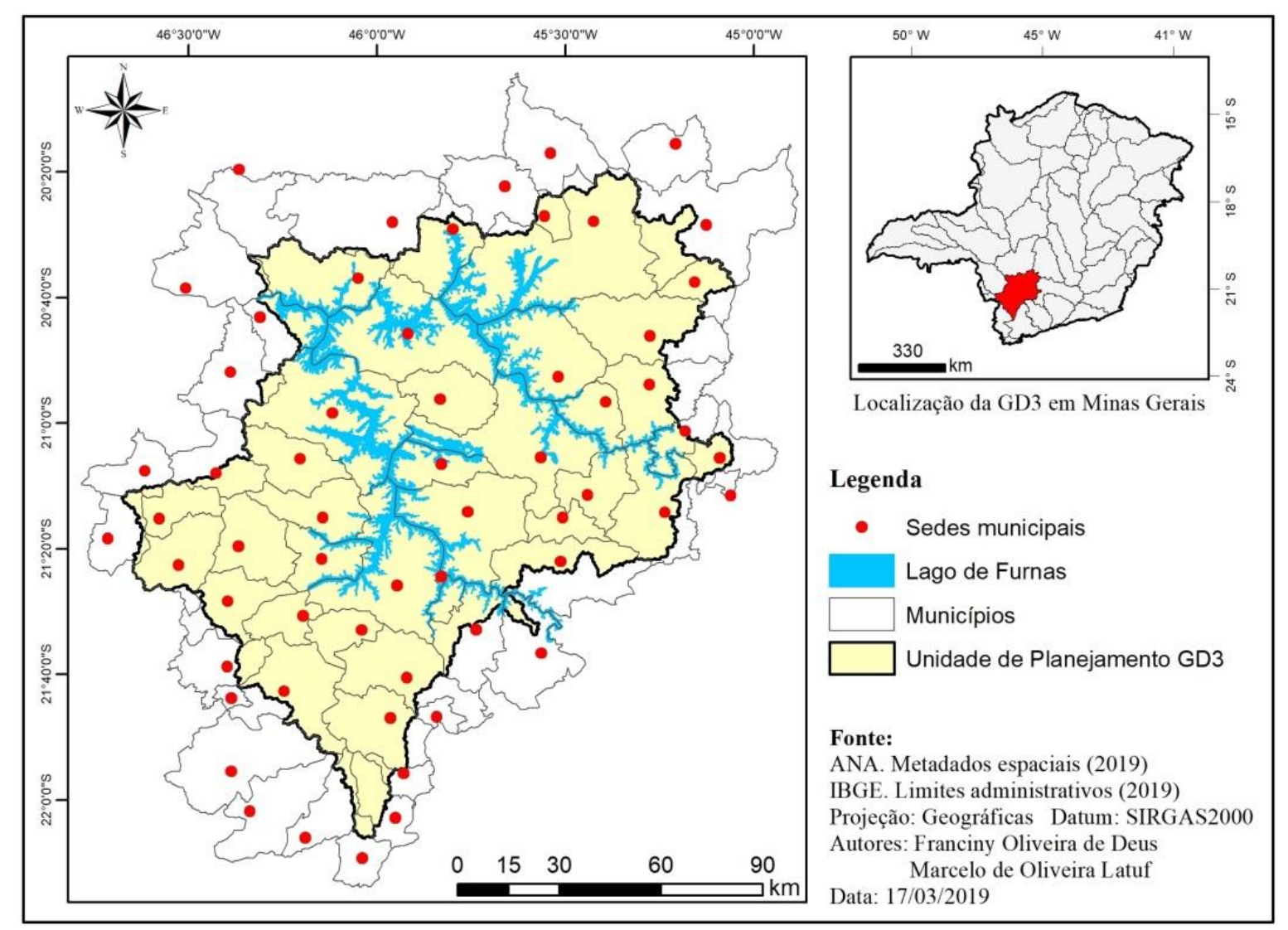

Figura 1 - Hidrografia principal da Unidade de Gestão GD3.

Fonte: Autores, 2019.

De forma geral, o clima predominante na área de estudo é o Tropical de Altitude, que se caracteriza por ser mesotérmico, úmido, com chuvas torrenciais; chuvas orográficas ou de relevo (resultante do relevo; geralmente a orográfica é torrencial). Esse clima também apresenta como característica importante temperaturas amenas com poucas variações, além de chuvas no verão e seca no inverno, o que corresponde, segundo a classificação de Köppen (1948), ao clima do tipo Tropical (Aw) e Tropical de Altitude (Cwb).

A temperatura média anual oscila entre 21 e $23^{\circ} \mathrm{C}$. O verão e a primavera são os períodos mais quentes, quando as máximas diárias variam em torno de 28 e $30^{\circ} \mathrm{C}$. A precipitação medi anual varia entre 1300 e $1600 \mathrm{~mm}$. O trimestre mais seco ocorre nos meses de junho, julho e agosto com 
valores médios da ordem de $60 \mathrm{~mm}$. O trimestre mais úmido ocorre nos meses de dezembro, janeiro e fevereiro, com valores médios de 750mm (PDRH FURNAS, 2013).

\section{ATIVIDADE DESENVOLVIDA E VOLUME CONSUMIDO}

Foram analisadas 135 outorgas superficiais para os diferentes usos de recursos hídricos (PDRH FURNAS, 2013). De acordo com a Figura 2, o setor de abastecimento público, mesmo com apenas $8,15 \%$ das outorgas, supera em vazão as outorgas destinadas à irrigação. Grande parte da vazão outorgada na bacia está distribuída entre o abastecimento público com 46,65\% e irrigação com $36,41 \%$.

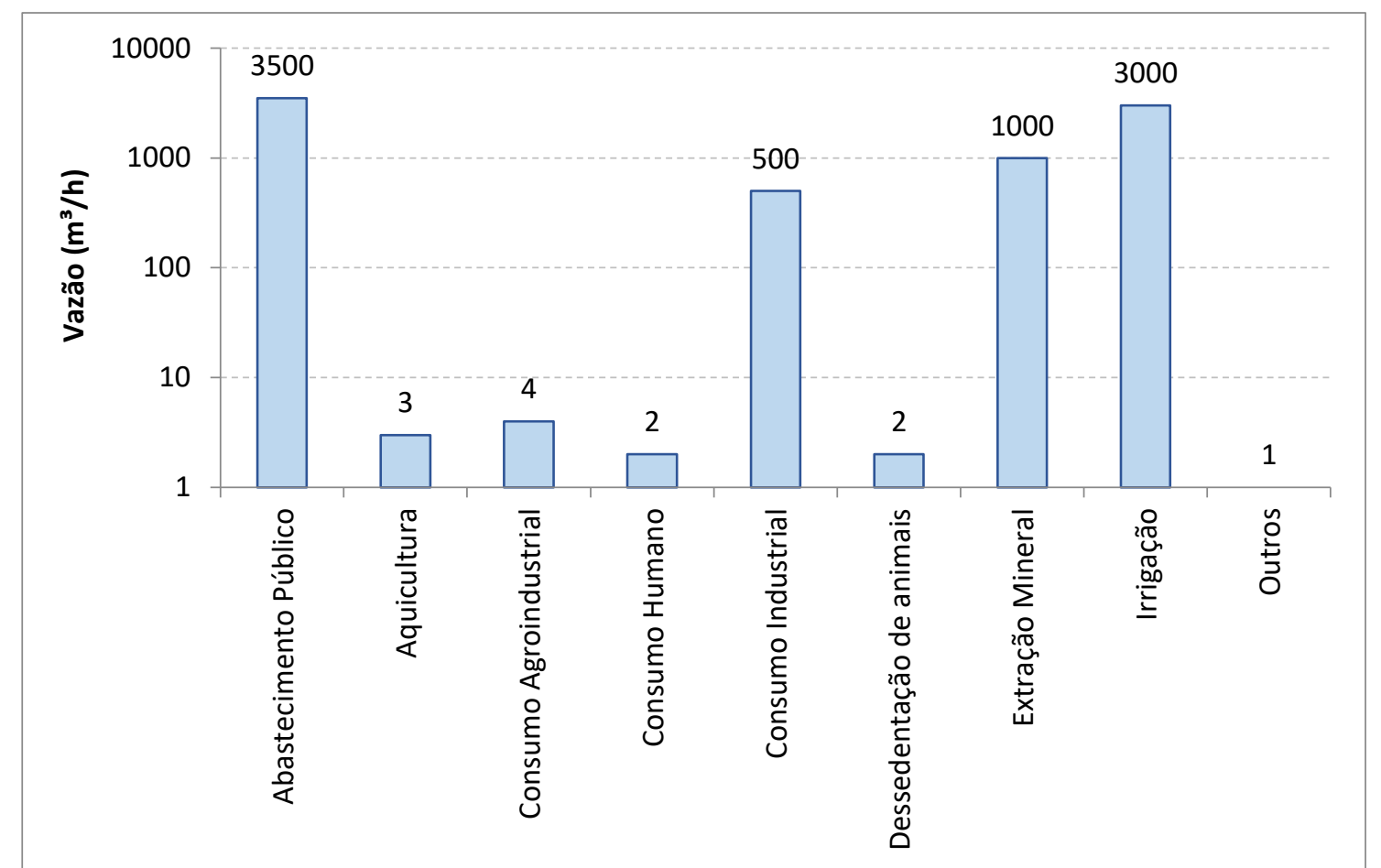

Figura 2 - Vazão outorgada pelo IGAM por uso de água superficial da Unidade de Gestão GD3. Fonte: Adaptado de IGAM, 2011.

É possível perceber que a vazão outorgada pelo IGAM por uso de água superficial da Unidade de Gestão GD3 para a piscicultura foi pequena, tal fato vem acarretando preocupação para os produtores de peixes, que com o indeferimento de outorga não conseguem expandir o cultivo.

Em relação à distribuição espacial, vale ressaltar que aproximadamente $57 \%$ de toda vazão outorgada na bacia concentram-se em apenas cinco municípios. Boa Esperança possui, também, a maior parcela da vazão, com 13,66\%, porém Formiga, Muzambinho, Três Pontas e Campo Belo também apresentam vazões consideráveis, próximas à linha de $800 \mathrm{~m}^{3} / \mathrm{h}$.

Para os recursos hídricos subterrâneos, foram concedidas 149 outorgas e 152 certidões de uso insignificante, desde março de 2002 a agosto de 2008. A Tabela 1 apresenta o número de 
outorgas concedidas e a vazão total outorgada por cada uso das águas subterrâneas. Em relação à distribuição espacial por municípios da vazão outorgada, os principais municípios detentores de outorgas e vazão são Alfenas, Campo Belo, Carmo do Rio Claro e, com maior destaque, Formiga, que apresenta 26,17\% do número de outorgas e 26,65\% da vazão total outorgada (PDRH FURNAS, 2013).

Tabela 1 - Número de outorgas concedidas pelo IGAM por uso e vazão outorgada.

\begin{tabular}{|c|c|c|c|c|}
\hline \multirow{2}{*}{ USO } & \multicolumn{2}{|c|}{$\mathrm{N}^{\circ}$ DE OUTORGAS } & \multicolumn{2}{|c|}{ VAZ $\tilde{A} O\left(\mathbf{m}^{3} / \mathbf{h}\right)$} \\
\hline & ABSOLUTO & PORCENTAGEM & ABSOLUTO & PORCENTAGEM \\
\hline $\begin{array}{c}\text { Abastecimento } \\
\text { público }\end{array}$ & 8 & 5,37 & 105,1 & 11,50 \\
\hline $\begin{array}{c}\text { Consumo } \\
\text { Agroindustrial }\end{array}$ & 2 & 1,34 & 7,3 & 0,80 \\
\hline $\begin{array}{l}\text { Consumo } \\
\text { humano }\end{array}$ & 34 & 22,82 & 176,9 & 19,35 \\
\hline $\begin{array}{l}\text { Consumo } \\
\text { industrial }\end{array}$ & 54 & 36,24 & 356,7 & 39,04 \\
\hline $\begin{array}{c}\text { Dessedentação } \\
\text { de animais }\end{array}$ & 12 & 8,05 & 93,5 & 10,23 \\
\hline Irrigação & 9 & 6,04 & 36,1 & 3,95 \\
\hline $\begin{array}{l}\text { Lavagem de } \\
\text { veículos }\end{array}$ & 30 & 20,13 & 138,2 & 15,12 \\
\hline
\end{tabular}

Fonte: Adaptado de IGAM, 2011.

Em algumas áreas pertencentes às bacias hidrográficas do Estado de Minas Gerais observam-se situações de indisponibilidade hídrica, quando a somatória das demandas por água por parte de diversos usuários requerentes é superior àquela vazão ou volume de recursos hídricos disponível para a outorga. O IGAM poderá, nesses casos, declarar área de conflito, após a análise dos estudos existentes relativos à disponibilidade hídrica e relativos aos usuários e suas respectivas demandas de água. A outorga, segundo Silva e Monteiro (2004), deve ser vista como um instrumento da alocação de água entre os mais diversos usos dentro de uma bacia hidrográfica. Essa alocação (distribuição) de água deve buscar os seguintes objetivos mínimos: atender às necessidades ambientais, econômicas e sociais por água; reduzir ou eliminar os conflitos entre usuários da água e possibilitar o planejamento das demandas futuras a serem atendidas.

$\mathrm{Na}$ análise dos processos de outorga torna-se necessária, em casos determinados, a vinculação de cuidados e/ou ações condicionantes a serem atendidas pelos usuários após a publicação da respectiva Portaria de outorga de direito de uso de recursos hídricos. Tais condicionantes devem referir-se ao monitoramento da quantidade, da qualidade e do regime das águas, de tal forma que a intervenção autorizada não comprometa outros usos concomitantes dos recursos hídricos, não cause impactos inapagáveis aos fluxos residuais e ao meio biótico ainda que atendam às recomendações da autoridade outorgante, de forma a possibilitar a continuidade da intervenção, quando da análise de um pedido de renovação da outorga. 
Na piscicultura a preocupação gira em torno do lançamento de efluentes. De acordo com o Manual Técnico e Administrativo de Outorga de Direito de Uso de Recursos Hídricos no Estado de Minas Gerais (IGAM, 2010), no artigo $2^{\circ}$ da DN CERH n 26/2008 está estabelecido que, para a análise do requerimento de outorga para o lançamento de efluentes, deve-se ter como referência o parâmetro Demanda Bioquímica de Oxigênio (DBO). A outorga deverá ser analisada em função da vazão de diluição, ou seja, a quantidade de água necessária para a diluição da concentração de DBO.

\subsection{Projeto de monitoramento e gestão ambiental da aquicultura do reservatório de Furnas}

O objetivo geral do Projeto é desenvolver um modelo para monitoramento e avaliação de impactos na criação de peixes em tanques-rede, assim como a adoção de Boas Práticas de Manejo (BPM) para a gestão ambiental de Parques Aquícolas (PROJETO DE MONITORAMENTO E GESTÃO AMBIENTAL DA AQUICULTURA DO RESERVATÓRIO DE FURNAS, 2012). De acordo com a EMATER (2017), a piscicultura vem se consolidando como importante atividade econômica na agropecuária de Minas Gerais. Segundo dados do IBGE (2016), o estado passou a ocupar o sexto lugar no ranking nacional dos maiores criadores de peixe do país. Em 2016, a produção de peixes em Minas Gerais foi de 32,8 mil toneladas, um crescimento de 48,4\% em relação a 2015, quando o estado produziu 22,1 mil toneladas.

Nesse sentido se faz necessário adotar práticas de manejo sustentável para que não ocorram danos à capacidade regenerativa do sistema. A expansão dos sistemas de aquicultura intensiva em tanques redes é frequentemente acompanhada de degradação do ambiente natural nas imediações da área de cultivo (BEVERIDGE, 1996). Pode ocorrer a contaminação dos corpos hídricos através dos resíduos presentes nos efluentes da aquicultura.

Para Starling, Pereira e Angelini (2005), os resíduos do cultivo, sob a forma de água, incorporando fezes dos peixes, resíduos urinários e ração não consumida, entram nos corpos d'água e os materiais particulados sedimentam e se acumulam no fundo do ecossistema. A acumulação de matéria orgânica aumenta o consumo de oxigênio dos sedimentos, levando, em muitos casos, a um hipolimnion anóxico, que gera consequências ecológicas negativas tais como mudanças de espécies e desequilíbrios no funcionamento de todo o ecossistema.

A liberação de nutrientes dissolvidos, como fosfato e amônia, pode estimular a produção primária do fitoplâncton, sendo que o aumento da biomassa algal acarreta a elevação do consumo de oxigênio durante a decomposição, acelerando o conhecido processo de eutrofização dos ambientes lacustres. Estudos experimentais realizados no Lago Kariba por Troell e Berg (1997) indicaram que sistemas tropicais apresentam uma proporção de liberação de fosfato dissolvido 
relativamente maior, embora com uma acumulação de carbono e nutrientes comparativamente menor que os sistemas temperados, como resultado de maiores temperaturas e processos mais acelerados de reciclagem desses nutrientes nos trópicos.

Portanto, uma das principais desvantagens da criação de peixes diz respeito a seus produtos metabólicos: ração não ingerida e os nutrientes inorgânicos dissolvidos excretados com as fezes que permanecem na água (PAGAND et al., 2000).

De acordo com o Projeto de Monitoramento e Gestão Ambiental da Aquicultura do Reservatório de Furnas (2012), ao longo do ano de 2012 foram realizadas quatro Campanhas de Campo (CC) no reservatório de Furnas, com o objetivo principal de fazer um diagnóstico produtivo da piscicultura no local, servindo de base para a escolha do PA objeto de estudo. Durante as CC foram realizadas atividades de coleta de dados sociais, econômicos e produtivos das pisciculturas visitadas, assim como o reconhecimento das características do local de produção e do seu entorno.

Todas as CC foram realizadas em parceria com a Empresa de Pesquisa Agropecuária de Minas Gerais (Epamig), o que permitiu que as equipes somassem esforços para a execução conjunta com o Projeto Furnas e do projeto de "Ordenamento da Implantação e do Desenvolvimento da Piscicultura Intensiva nos Reservatórios de Furnas, Três Marias e Nova Ponte”, coordenado pela pesquisadora da EPAMIG Elizabeth E. Lomelino, com subsídios da Fundação de Amparo à Pesquisa do Estado de Minas Gerais (FAPEMIG). Além da Epamig, a Empresa de Assistência Técnica e Extensão Rural do Estado de Minas (Emater-MG) também foi parceira na execução das CC, auxiliando na identificação e aproximação com os produtores. A Tabela 2 mostra as pesquisas realizadas nos munícipios de Guapé, Formiga, Aguanil, Boa Esperança, Carmo do Rio Claro, Campo do Meio e Campos Gerais.

É importante que os produtores de peixes utilizem uma boa forma de manejo, evitando assim a contaminação dos corpos hídricos onde ocorre o cultivo. O entorno do Reservatório de Furnas tem grande potencial para essa prática, já que, segundo Starling, Pereira e Angelini (2005), no caso específico do Reservatório da UHE Furnas, pode-se constatar haver um comportamento bastante regular na dinâmica sazonal de oscilação de cota ao longo dos anos. Em meados de novembro e início de dezembro ocorre o início de subida dos níveis do reservatório, mantendo os níveis mais elevados no período compreendido entre março e julho, quando então o reservatório é deplecionado até meados de novembro/início de dezembro, reiniciando o ciclo. Para Duarte (2003), "uma das variáveis de maior importância na avaliação de capacidade de suporte é a taxa de renovação da água, representada pelo tempo de residência do corpo hídrico". 
Tabela 2 - Dados de Parques Aquícolas no reservatório de Furnas.

\begin{tabular}{|c|c|c|c|c|c|c|c|}
\hline PA & Municípios & $\underset{\left(\mathbf{k m}^{2}\right)}{\mathrm{AII}}$ & $\begin{array}{l}\text { AID } \\
\text { (ha) }\end{array}$ & $\begin{array}{l}\text { Perímetro } \\
(\mathbf{m})\end{array}$ & $\begin{array}{c}\mathbf{N}^{\mathbf{0}} \mathrm{de} \\
\text { Áreas } \\
\text { Aquícolas } \\
\text { (Polígonos) }\end{array}$ & $\begin{array}{c}N^{0} \text { de } \\
\text { tanques }\end{array}$ & $\begin{array}{l}\text { Produção } \\
\text { estimada } \\
\text { (t/ano) }\end{array}$ \\
\hline Guapé I & Guapé & 5,2 & 95,4 & 7,31 & 2 & 5.956 & 2.383 \\
\hline Guapé II & Guapé & 71,6 & 274,5 & 10,83 & 2 & 13.293 & 5.317 \\
\hline Guapé III & Guapé & 42,1 & 59,6 & 3,71 & 1 & 4.676 & 1.870 \\
\hline Guapé IV & Guapé & 5,7 & 47,5 & 3,77 & 1 & 2.816 & 1.126 \\
\hline S. Hilário & Formiga & 24,2 & 228,7 & 6,64 & 2 & 37.353 & 14.941 \\
\hline $\begin{array}{c}\text { Boa } \\
\text { Esperança }\end{array}$ & $\begin{array}{l}\text { Aguanil/Boa } \\
\text { Esperança }\end{array}$ & 10,8 & 49,1 & 3,29 & 1 & 5.490 & 2.196 \\
\hline $\begin{array}{l}\text { Total rio } \\
\text { Grande }\end{array}$ & & 159,6 & 754,8 & 35,55 & 9 & 69.584 & 27.833 \\
\hline \multicolumn{8}{|c|}{ Rio Sapucaí } \\
\hline Sapucaí I & Guapé & 9,2 & 146,5 & 6,24 & 2 & 12.186 & 4.874 \\
\hline Sapucaí II & Guapé & 12,2 & 10,3 & 7,13 & 2 & 8.929 & 3.491 \\
\hline Sapucaí III & $\begin{array}{l}\text { Carmo do } \\
\text { Rio Claro }\end{array}$ & 13,5 & 67,4 & 3,54 & 1 & 10.745 & 4.298 \\
\hline Sapucaí IV & $\begin{array}{l}\text { Carmo do } \\
\text { Rio Claro }\end{array}$ & 2,9 & 32 & 2,76 & 1 & 6.750 & 2.700 \\
\hline $\begin{array}{l}\text { Carmo do } \\
\text { Rio Claro }\end{array}$ & $\begin{array}{l}\text { Carmo do } \\
\text { Rio Claro }\end{array}$ & 11,8 & 73,6 & 3,60 & 1 & 4.975 & 1.990 \\
\hline Itaci & $\begin{array}{l}\text { Carmo do } \\
\text { Rio Claro }\end{array}$ & 30,1 & 37,3 & 3,08 & 1 & 1.361 & 545 \\
\hline Sta. Quitéria & $\begin{array}{l}\text { Carmo do } \\
\text { Rio Claro } \\
\text { Carmo do }\end{array}$ & 24,9 & 367,2 & 9,69 & 2 & 31.030 & 12.412 \\
\hline $\begin{array}{c}\text { Campo do } \\
\text { Meio }\end{array}$ & $\begin{array}{l}\text { Rio Claro/ } \\
\text { Campo do } \\
\text { Meio }\end{array}$ & 57,8 & 978,0 & 16,69 & 2 & 6.156 & 2.462 \\
\hline $\begin{array}{c}\text { Barranco } \\
\text { Alto I }\end{array}$ & $\begin{array}{l}\text { Carmo do } \\
\text { Rio Claro }\end{array}$ & 88,7 & 306,2 , & 7,38 & 2 & 6.156 & 2.462 \\
\hline $\begin{array}{c}\text { Barranco } \\
\text { Alto II }\end{array}$ & $\begin{array}{c}\text { Campos } \\
\text { Gerais }\end{array}$ & 29,2 & 221,5 & 9,74 & 2 & 1965 & 786 \\
\hline $\begin{array}{c}\text { Total rio } \\
\text { Sapucaí } \\
\text { Total }\end{array}$ & & 280,3 & 2.240 & 69,85 & 16 & 128.914 & 51.485 \\
\hline $\begin{array}{c}\text { Reservatório } \\
\text { de Furnas }\end{array}$ & & 439,9 & 2994,8 & 105,40 & 25 & 198.498 & 79.318 \\
\hline
\end{tabular}

De acordo com a EMATER-MG (2017), o aumento verificado na produção mineira é o resultado da maior integração entre criadores e o poder público.

A participação dos produtores na tomada de decisões vem crescendo. E o Estado busca adequar a legislação à realidade dos produtores para incentivar as criações, como exemplo temos a consulta pública proposta pela Secretaria de Estado de Meio Ambiente para alteração da Deliberação Normativa (DN) 74 que deverá trazer grandes avanços na legalização da piscicultura em Minas (EMATER-MG, 2017). 


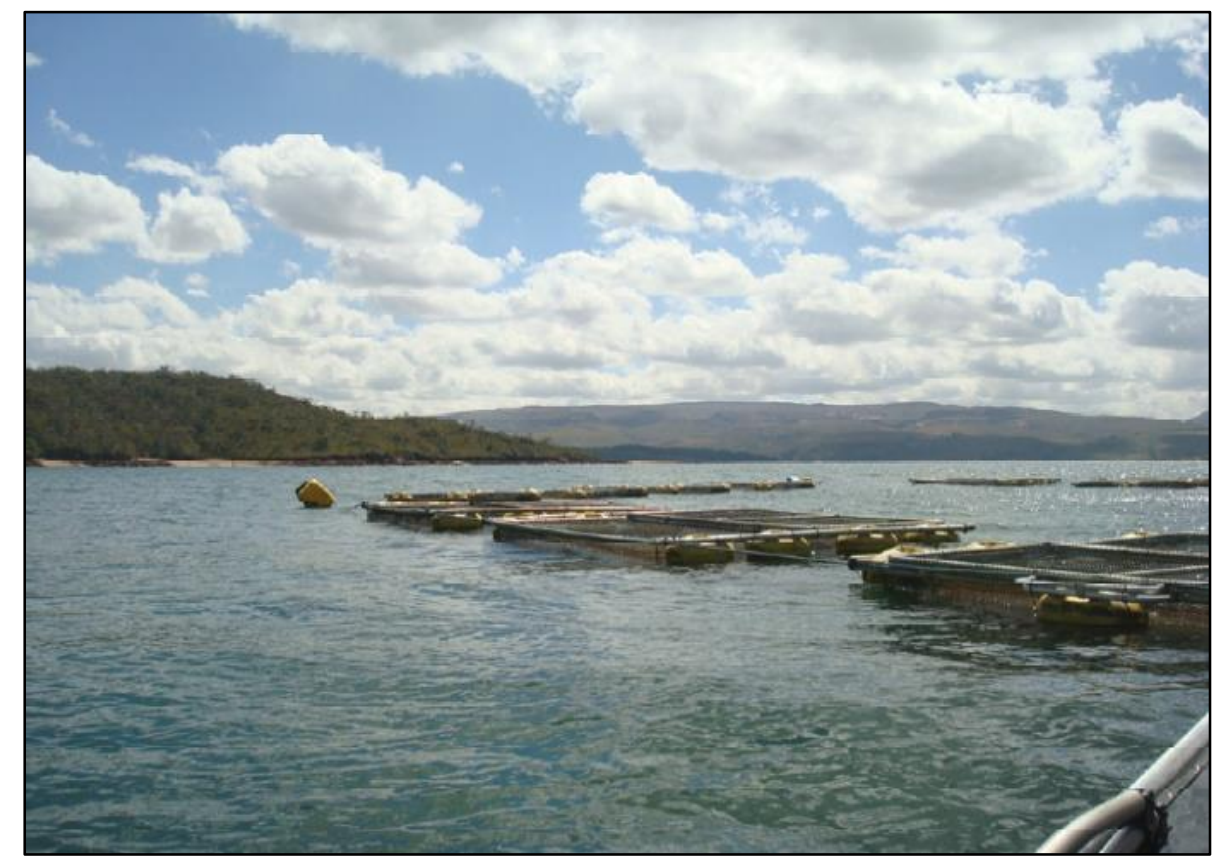

Figura 3 - Imagem de piscicultura no reservatório de Furnas

Fonte: Adaptada de Projeto de monitoramento e gestão ambiental da aquicultura do reservatório de Furnas, 2012.

O entorno do Reservatório de Furnas tem potencial para expandir o cultivo de peixes, no entanto, é necessário que os piscicultores procurem aperfeiçoar o manejo, para que não contamine os corpos de água. Esse setor da economia pode aumentar a produção, dependendo do deferimento de outorgas, por isso tal ato administrativo possui papel fundamental no crescimento da piscicultura.

\section{CONSIDERAÇÕES FINAIS}

A Outorga de Direito de Uso de Recursos Hídricos constitui um instrumento fundamental no que se refere aos mecanismos de controle dos usos da água. Ela é um instrumento articulado com o Plano de Recursos Hídricos, o Enquadramento e a Cobrança pelo Uso da Água. Uma vez que os critérios de alocação de água serão definidos pelo Plano, esses critérios deverão respeitar as metas de qualidade do Enquadramento e, ainda, deverão determinar os quantitativos a serem arrecadados pela Cobrança.

É de responsabilidade do poder público assegurar o acesso à água, mediante o uso racional e eficiente das águas, compatibilizando as demandas às disponibilidades hídricas, nas respectivas bacias hidrográficas, para os diversos usos a que se destinam. A aplicação correta do instrumento da outorga, mais do que um ato de regularização ambiental, destina-se a disciplinar a demanda crescente das águas superficiais e subterrâneas entre os diversos usos concorrentes e ainda a indicar aos usuários de recursos hídricos a necessidade da adoção de práticas modernas e conservacionistas. 
No que tange à piscicultura a outorga é um importante instrumento de adequação das práticas do cultivo, pois é necessário o manejo sustentável para evitar a contaminação dos corpos hídricos e promover a regeneração do sistema produtivo.

No entorno do Reservatório de Furnas a atividade da aquicultura vem se intensificando cada dia mais, para tanto os produtores devem aderir a práticas de manejo sustentável para que não ocorra degradação e contaminação dos corpos hídricos.

\section{REFERÊNCIAS}

PDRH FURNAS. 2013. Plano Diretor de Recursos Hídricos da Bacia Hidrográfica do Entorno do Lago de Furnas: Relatório Parcial 1: Diagnóstico da Bacia Hidrográfica. Alfenas: ALAGO. Disponível em: <http://portalinfohidro.igam.mg.gov.br/planos-diretores/bacia-hidrográfica-do-riogrande/ugrhgd3entorno-do-reservatório-de-furnas/8261->. Acesso em: 14 mar. 2019.

BEVERIDGE, M. C. M. Cage aquaculture. 1. ed. Oxford: Fishing News Books, 1996. 346p.

BRASIL. Congresso Nacional. Lei $n^{\circ}$. 9.433, de 08 de janeiro de 1997. Dispõe sobre a Política Nacional de Recursos Hídricos e dá outras providências. Diário Oficial da República Federativa do Brasil, Poder Executivo, Brasília, DF, 09 jan. 1997. Disponível em: <http://www.senado.gov.br>. Acesso em: 15 mar. 2019.

BRASIL. Constituição (1988). Constituição da República Federativa do Brasil, 1988. Brasília: Senado Federal, 1988. Disponível em: <http://www.senado.gov.br>. Acesso em: 14 mar. 2019.

DUARTE, P.; MENESES, R.; HAWKINS, A. J. S.; ZHU, M.; FANG, J.; GRANT, J. Mathematical modelling to assess the carrying capacity for multi-species culture within coastal waters. Ecological Modelling, v. 168, p. 109-143, 2003.

EMATER. EMPRESA DE ASSISTÊNCIA TÉCNICA E EXTENSÃO RURAL DO ESTADO DE MINAS GERAIS. 2017. Disponível em: <http://www.emater.mg.gov.br>. Acesso em: 15 mar. 2019.

IBGE. INSTITUTO BRASILEIRO DE GEOGRAFIA E ESTATÍSTICA - IBGE, 2009. Disponível em: <https://www.ibge.gov.br>. Acesso em: 15 mar. 2019.

KÖPPEN, W. Climatologia: com um estúdio de los climas de la tierra. 1. ed. Cidade do México: Fondo de Cultura Economica, 1948. 478p.

MEIRELLES, H. L. Direito administrativo brasileiro. 32. ed. São Paulo: Malheiros, 2006. 1016p.

MINAS GERAIS. Assembleia Legislativa. Lei no . 13.199, de 29 de janeiro de 1999. Dispõe sobre a Política Estadual de Recursos Hídricos e dá outras providências. Diário Oficial do Estado de Minas Gerais. Belo Horizonte, 30 jan. 1999. Disponível em: 〈http://www.almg.gov.br〉. Acesso em: 15 mar. 2019.

Assembleia Legislativa. Lei $n^{\circ} .180$ de 20 de janeiro de 2011. Dispõe sobre a estrutura orgânica da Administração Pública do Poder Executivo do Estado de Minas Gerais e dá outras 
providências. Diário Oficial do Estado de Minas Gerais. Belo Horizonte, 21 jan. 2011. Disponível em: <http://www.almg.gov.br>. Acesso em: 13 mar. 2019.

Plano estadual de recursos hídricos. Belo Horizonte, 2011. Disponível em: <http://www.igam.mg.gov.br/gestao-das-aguas/plano-de-recursos-hidricos>. Acesso em: 13 mar. 2019.

Manual técnico e administrativo de outorga de direito de uso de recursos hídricos no estado de Minas Gerais. Belo Horizonte, 2010a. Disponível em: <http://www.meioambiente.mg.gov.br/outorga/manual-de-outorga>. Acesso em: 13 mar. 2019.

PAGAND, P.; BLANCHETON, J. P; LEMOALLE, J.; CASELLAS, C. The use of high rate algal ponds for the treatment of marine effluent from a recirculating fish rearing system. Aquaculture Research, v. 31, p. 729-736, 2000.

PROJETO FURNAS. Desenvolvimento de sistema de monitoramento para gestão ambiental da Aquicultura no reservatório de Furnas: suporte para a consolidação de indicadores para o plano de monitoramento e gestão ambiental da Aquicultura: relatório II: atividades 2012. Brasília: Ministério da Pesca e da Aquicultura, 2014. 221p.

STARLING, F.; PEREIRA, C. E. ANGELINI, R. Estudo técnico-científico visando à delimitação de parques aquícolas no Lago da Usina Hidroelétrica de Furnas-MG. Governo de Minas. 2005.

SILVA, L. M. C.; MONTEIRO, R. A. Outorga de direito de uso de recursos hídricos: uma das possíveis abordagens. In: MACHADO, C. J. S. (Org.). Gestão de águas doces: usos múltiplos, políticas públicas e exercício da cidadania no Brasil. Rio de Janeiro: Interciência, 2004. cap. 5. p. 135-178.

TROELL, M.; BERG, H. Cage fish farming in the tropical lake Kariba, Zimbabwe: impacts and biogeochemical changes in sediments. Aquaculture Research, v. 28, p. 527-544, 1997.

Trabalho recebido em 12/07/2019

Trabalho aceito para publicação em 13/07/19 